\title{
Ferreting Out Capstone Design Issues in Large Scale, Complex Problems using the House of Quality
}

\author{
John A. Marin, James E. Armstrong, Jr. \\ Department of Systems Engineering \\ United States Military Academy
}

\section{Introduction}

An engineering capstone design experience is the crowning achievement in a student's academic curriculum, and integrates the principles, concepts, and techniques explored in earlier engineering courses. Systems engineering concerns the design of systems which are large-scale, complex and multi-disciplinary and is defined as "the design, production, and maintenance of trustworthy systems within time and cost constraints." [1] Successful real-world design is meeting or exceeding the effective needs of the client and stakeholder group in a cost-effective, high quality manner. However, it is usually not possible to resolve every aspect of a complex, real-world effective need in a one or even two semester capstone design course. In the Department of Systems Engineering at the United States Military Academy in West Point, New York, we mandate the application of the House of Quality in order to ferret out or discover those key criteria that are critical to the success or failure of a given system.

\section{Ferreting Out Design Issues with the House of Quality}

We introduce a five step process for ferreting out, or mining the key design issues in a complex system in the hope students will discover a nugget that eventually leads to a successful design and unique educational experience. The five step process we use to incorporate the House of Quality in capstone design is depicted below in Figure 1 and subsequently explained.

Step 1: Scope and Bound the Problem
Step 2: Create a Value System
Step 3: Construct a House of Quality
Step 4: Analyze the House of Quality to Ferret Key Design Issues
Step 5: Assess Student Capabilities and Select Key Design Issues

Figure 1: Five step process for ferreting out the key design issues.

\section{A. Scope and Bound}

The first step in successfully bringing to light the key design issues is to scope and bound the problem. To scope a design project means to understand why the project is necessary, who will use the results of the design effort and how they will use them, what the stakeholders intend to accomplish with the project, and how to measure project success. In systems engineering terms, this means identifying the needs, objectives, and criteria for the design. The needs tell why the project is necessary or what void or deficiency the design will fill or improve in some way. A need is a lack of something required or desired. 
To bound a design problem means to understand the limitations associated with the project, the changes that can be made to achieve desired objectives, and the important quantities that are likely to change as a result of the project. In systems engineering terms, this means identifying the components, constraints, parameters, and variables for the project.

\section{B. Create a Value System}

Value system design involves defining a set of objectives and related design criteria that identify what the interested parties want to accomplish and how to measure and evaluate a design alternative's impact on the objectives. Note this is very different from what often happens in traditional engineering design problems where students quickly jump to preconceived alternatives and set about finding ways or measures to prove their design is the best.

Objectives describe, in statements, everything that the design project is intended to accomplish. Criteria measure success in achieving the objectives. Useful criteria are measures that take a quantifiable form with both a clear definition of the measure and the units associated with the measure. One technique that is often used is to create a hierarchy or tree of one of the elements, such as an objective tree. Other techniques include tables and matrices that relate one set of elements to another, such as relating objectives with their associated criteria. The objectives eventually become the Whats of the House of Quality while the criteria become the Hows.

\section{Construct a House of Quality}

References such as [2], [3] and [4] provide instructions for constructing a House of Quality. To successfully build a House of Quality, students must thoroughly understand the problem. The Whats (Objectives) and Hows (Criteria) of the House are obtained through careful research and the application of applicable modeling tools (see [1], [5]). Students develop the objective weightings and interaction assignments, which are reviewed by the instructor, and presented to the client. In almost every case, the client marvels at the methodological approach employed by the student in constructing the House of Quality.

\section{Analyze the House of Quality}

Constructing and analyzing a House of Quality is an iterative process. For example, constructing the roof and assessing interactions among the Hows usually leads to the identification of more criteria. Thus, we feel one student in a project group should not be saddled with the task of filling-in the House. Rather, we encourage students to view this as a brainstorming session.

After students identify the key criteria that have the largest impact on the system, the students develop a plan to model these criteria in regards to existing systems and competing alternatives. A beneficial side-effect of the analysis is the identification of those key areas of the project that have the potential to add the most value. Thus, the House of Quality assists students in designing alternative systems to meet the needs of the stakeholders. 
Analyzing the House of Quality also involves assessing the relative importance of the Whats or objectives. Students are taught the term "relative" is key since importance ratings assigned to the objectives are not absolute. Students learn to track key criterion through the roof, and to identify negative interactions with other variables. Finally, for most of the design problems we encounter, there are existing systems that students use as "competitors." The competitors serve as a benchmark against which students can compare their alternative system designs.

\section{E. Assess Student Capabilities and Select Key Design Issues}

Students usually identify more objectives and associated criteria than they can reasonably be expected to model and evaluate within the limits of the course. Thus, faculty must assist students in selecting those key criteria that will become the focus for the development and assessment of alternatives. Available time, student background, and applicable resources impact the selection of the key design criteria. Since the capstone program integrates the principles, concepts, and techniques explored in earlier courses, we try to limit the amount of new techniques students will have to learn to model and evaluate selected criteria. Otherwise, students invariably ask the question, "Why did I have to take all those other courses?"

Faculty, in consultation with the students and the client, direct the focus of the project at this stage. Using the House of Quality, and emphasizing the relative nature of the importance ratings, design issues are selected for which faculty believe the students are prepared. It must be emphasized the faculty do not take ownership of the project at this stage, rather, faculty provide guidance gained from experience that students usually do not posses.

\section{An Example of Ferreting Design Issues using the House of Quality}

The Objective Individual Combat Weapon (OICW) is an advanced weapon system that proposes to increase the lethality of the soldier. The conceptual design of an OICW is a dual-barreled weapon that in addition to firing a standard $5.56 \mathrm{~mm}$ bullet is capable of firing a $20 \mathrm{~mm}$ high explosive, air bursting munition. The air bursting munition is effective against protected enemy soldiers, such as those in foxholes, behind building corners, or in buildings behind windows. The problem, as described by the client", is that "we have the technology, now what do we do with it?"

The students initially outscoped (step 1) the problem by observing that the overall effectiveness of the soldier cannot be separated from the overall effectiveness of the squad because at the lowest level, the Army fights as squads of nine soldiers. Based on this premise, the students decided to model and assess different squad alternatives in order to measure the impact of the OICW. For example, one alternative would give every soldier in a nine man squad an OICW; a second alternative has zero OICWs in the squad.

\footnotetext{
The client for this project was the Advanced Systems Concepts Office, US Army Armament Research, Development, and Engineering Command (ARDEC), Picatinny Arsenal, New Jersey. ARDEC was the recipient of the 1996 Presidential Award for Quality and is commanded by Brigadier General J.W. Boddie, Jr.
} 
The students next ascertained objectives and criteria relating to the project problem statement (step 2), and constructed a House of Quality (step 3). Since the actual House of Quality is too large to present in this paper, only a portion of the House of Quality is depicted below in Figure 2.

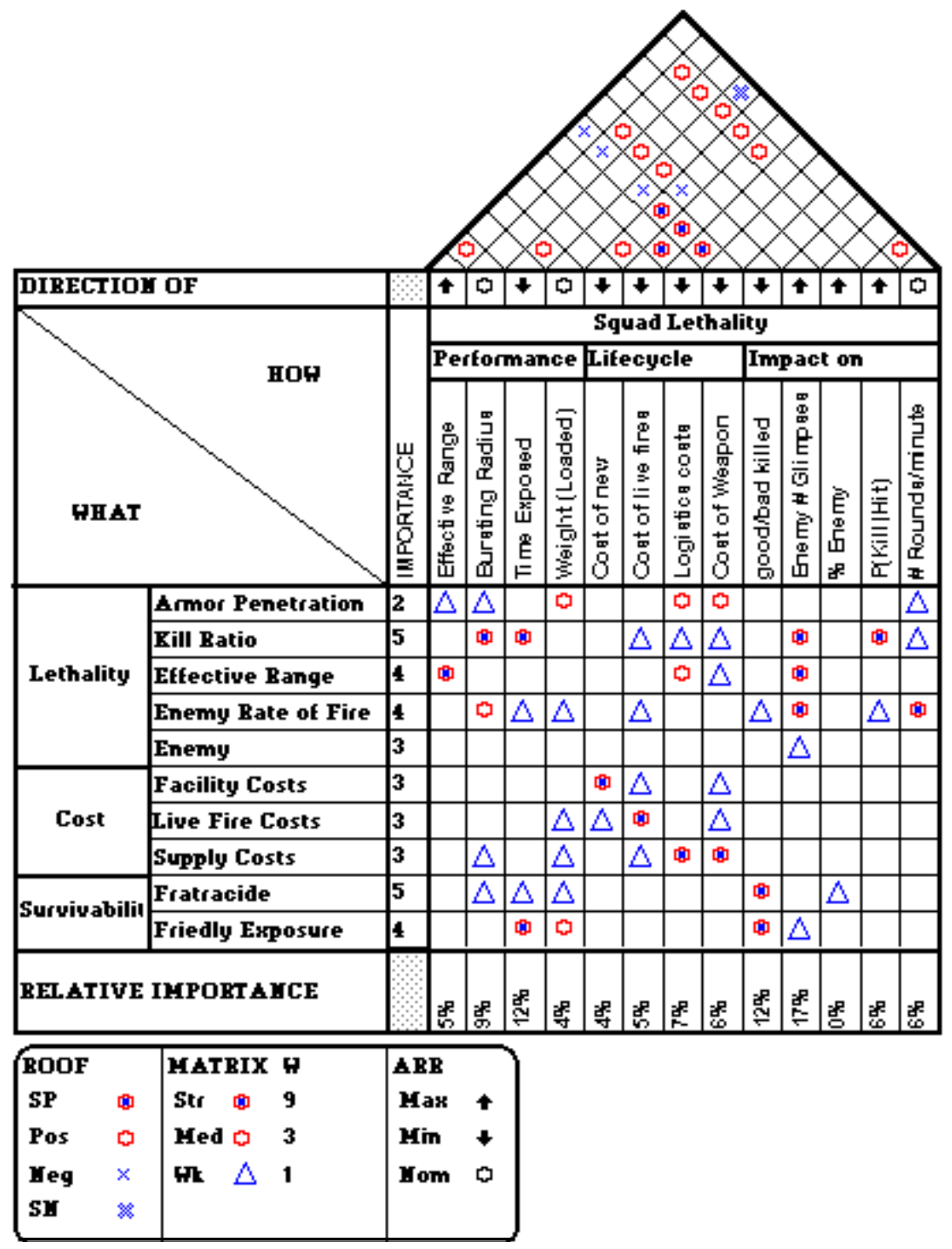

Figure 2: OICW House of Quality

Initially, the students identified many traditional measures of effectiveness associated with a soldier's individual weapon, such as, probability of hit ( $\mathrm{p}(\mathrm{hit})$ ), probability of a kill given a hit (p(kill|hit)), effective range of the weapon, and the force effectiveness ratio (friendly losses divided by enemy losses). However, since the OICW exhibited a bursting munition capability, the students developed some non-traditional measures of effectiveness concerning the enemy's ability to fire at friendly soldiers. In other words, if bullets are bursting over the head of enemy 
soldiers, the enemy may keep their heads down and covered and be less likely to fire at friendly soldiers.

Based on the relative weight of the Hows, the House of Quality assisted the students in identifying certain key criterion, such as the force effectiveness ratio, the rate at which the enemy detects friendly soldiers (glimpse rate), and training costs associated with the new weapon. The students then designed different plans to evaluate the key criteria (step 4). For example, students at West Point take an elective in combat modeling, and are exposed to the Janus Combat Simulation Model ${ }^{*}$. While Janus is capable of simulating and providing data concerning traditional measures of effectiveness, Janus does not permit individual weapons to employ air bursting munitions. Thus, to measure the effects of the $20 \mathrm{~mm}$ air bursting munition, students recommended writing a stand-alone simulation in Visual Basic. Finally, measuring the impact of a new weapon system on Army training resources would require extensive research concerning current Army facilities, including the design, construction, and operation of new rifle ranges (if a new weapon has a longer firing capability, existing ranges may be obsolete).

Since time did not permit students to design both a new infantry squad and the training facilities to support the squad, faculty involved with the project discussed these alternative plans with the client. The faculty recommended the students evaluate the OICW with the Janus combat simulation and create a second simulation using Visual Basic. Since the mission of West Point is to prepare young men and women to serve as officers in the Army, the faculty decided that a design project dealing with integrating the OICW into an infantry squad would be a better educational experience for the students than designing a training system to support a new weapon system (step 5). The client agreed, and inquired if students would be available the following year to undertake the "required training infrastructure" problem.

\section{Capstone Design Program Innovations}

As an institution, the United States Military Academy at West Point is committed to ensuring that a major outcome for all graduates is an understanding of the engineering thought process [6]. To support this goal, the Systems Engineering Department has instituted many innovations in order to ensure students are afforded an opportunity for a truly unique design experience. The House of Quality is one of these innovations. The following sections describe how the House of Quality is integrated into the capstone program. Additionally, other innovations used in the department are also briefly described (For a detailed explanation of these and additional innovations, the reader is referred to [7]).

The capstone design program for System Engineers at West Point is a two semester course, with each course representing 3.5 credit hours. Students participating in the capstone program are assigned to design teams with four individuals per team being the target number. Figure 3 below depicts a general framework for the progression of our capstone design experience and shows where the House of Quality is integrated into the design course.

\footnotetext{
* Janus is an interactive, two-sided, closed, stochastic, ground combat simulation featuring both precise statistical and animated output with color graphics. The Janus database can be manipulated by students to represent their battlefield system .
} 


\begin{tabular}{||c|l||}
\hline Lesson \# & TOPIC \\
\hline 1 st Semester & \\
\hline 1 & Course Introduction/Administration \\
\hline $3-6$ & Introduction to QFD \\
\hline $7-15$ & Problem Definition: \\
\hline $16-23$ & $\begin{array}{l}\text { Value System Design: House of } \\
\text { Quality }\end{array}$ \\
\hline $25-35$ & Synthesis of Alternatives \\
\hline $36-40$ & Phase I Completion \\
\hline 2 nd Semester & \\
\hline $1-5$ & Review \& Iterate on Phase I \\
\hline $6-25$ & Systems Modeling \\
\hline $25-30$ & Optimize Alternatives \\
\hline $30-35$ & Decision Making \& Planning For Action \\
\hline $38-40$ & Turn-in Final Project/Briefings \\
\hline
\end{tabular}

Figure 3: Framework for a 2-semester systems engineering capstone design program.

Lead Engineer: Each student is assigned the duties of lead engineer for at least one graded event. The lead engineer sets the goals for the groups and develops a syllabus for the given block of lessons. Additionally, the lead engineer is responsible for the timeliness and quality of any required turn-ins or briefings. Experience has shown students like the concept of a lead engineer because someone is always in charge and responsible for organizing the group.

After a student completes a rotation as lead engineer, the capstone instructor counsels the lead engineer on his or her performance. Questions we ask the lead engineer include: How do you think you performed as the lead engineer? How did the group perform? What are some areas you could have improved upon? and, Did you meet your goals?

Design Workshops. We found that giving students a number of class drops in a row (no attendance required for several lessons) was not very helpful. Feedback from students indicated they were not using the drops to make as much progress on design work as we had hoped. Instead they tended to get behind on their design project and focus on more pressing graded requirements. To counter this, we instituted design workshops where students must attend class, usually in a lab, and work in their design teams on their project. At least one of the instructors for each project is there to provide guidance if students encounter problems or have legitimate questions. Also, it provides instructors with many opportunities to observe ongoing design work. It is relatively easy for the instructor to determine how well various team members are contributing to the design work and how well the team works together. As the year progresses, generally less oversight of design workshops is required which is usually the reverse of traditional capstone courses.

Group Turn-In Grades: Instructors must decide how to apportion grades from group graded events to the individual group members. One obvious rule is to assign each member of a group the same grade for a group turn-in. In the Systems Engineering Department at West Point, 
instructors use a group survey form to solicit group members' perspective on individual group participation. Each group member fills out a matrix as depicted below in Figure 4 and assigns each member, including himself or herself, a grade based on a scale from 0 to 10 (where 0 equals "did not participate," and 10 is "excellent participant"). In order to ensure all students do not rate each other in the same category, no column is allowed to be marked more than once. In other words, each student is assigned a different rating.

\begin{tabular}{|l|l|l|l|l|l|l|l|l|l|l|l|}
\hline \multicolumn{1}{|c|}{ Poor } & \multicolumn{1}{c|}{ Fair } & \multicolumn{1}{c|}{ Ave. } \\
\hline Name & 0 & 1 & 2 & 3 & 4 & 5 & 6 & 7 & 8 & 9 & 10 \\
\hline & & & & & & & & & & & \\
\hline & & & & & & & & & & & \\
\hline & & & & & & & & & & & \\
\hline & & & & & & & & & & & \\
\hline
\end{tabular}

Figure 4: Group Survey Form Grade Matrix

Other questions on the group survey form include:

- To the best of your knowledge, list the total time you spent on the project.

- Overall, is your team working well together (Use a scale from 0 to 10 where 1 is for "not so well," and 9 is for "working very well")?

- Do you want to stay in the same group? YES or NO

- Would you want to work in this group again? YES or NO

The instructor may assign different members of the group a lower or higher grade based on their respective contribution and instructor observations of ongoing design work. Additionally, the instructor can address problems within a group early on.

Client Interaction. We strongly believe that client interaction is essential to a successful capstone experience. Our experience has been that student's interest in the project skyrockets after the initial client meeting because students now believe the project is relevant and worthwhile. Client interaction does not stop with the initial client meeting. The client should attend some student Interim Progress Reports, as well as the final technical briefing. Likewise, the students should visit the client's labs and offices, and get a taste for engineering in an industrial setting. Finally, students should be given the opportunity to interact with other professionals relating to the project in order to broaden their horizon.

Also, the client serves as an invaluable source regarding program assessment. We firmly believe that if a program continues to change and focus on meeting the needs of the industry it serves, the program will continue to remain relevant.

\section{Conclusion}

Successful real-world design is meeting or exceeding the effective needs of the client and stakeholder group in a cost-effective, high quality manner. However, it is usually not possible to resolve every aspect of a complex, real-world effective need in a one or even two semester 
capstone design course. This means to be successful in capstone designs that involve actual clients, it is important to identify some key design issues whose resolution will help the client considerably in making progress towards satisfying such a need.

One way, as we have shown, to ferret out or bring to light these key design issues is to use the House of Quality in a five step procedure of scoping and bounding the problem, determining a value system, constructing a House of Quality, analyzing the House of Quality to ferret out key design issues, and assessing student capabilities to successfully resolve the identified design issues. Consultations with the client can help prioritize and focus student efforts on design issues that really matter to the client and are within the capabilities of students to resolve given student and course constraints.

As we point out, this five step procedure does not ensure success by itself. It is still important to motivate and involve students in the design with innovative teaching methods and course administration techniques. Appointing, guiding, and rotating students in the role of lead engineer for their design team, facilitating design teamwork with design workshops, providing for quality client interactions with the students, and administering a supportive grading scheme have proven successful in our systems engineering capstone design work. The confidence, excitement, and commitment to engineering that students develop as a result of their capstone design experience of working on real problems with actual clients make for rich, intrinsic rewards for the students and faculty alike.

\section{References}

[1] A.P Sage, Systems Engineering, Wiley: New York, 1992.

[2] J.R. Hauser and D. Clausing, "The House of Quality," Harvard Business Review, May-June 1988, pp. 63-73.

[3] L.P. Sullivan, “Quality Function Deployment,” Quality Progress, June 1986, pp. 39-51.

[4] QS Software, QFD Designer User's Reference, American Supplier Institute: Rochester Hills, MI, 1995.

[5] J.E. Gibson, How to Do Systems Analysis, Unpublished Notes: Charlottesville, VA, 1991.

[6] United States Military Academy, Academic Program (Redbook), Academic Year 1997-1997, Office of the Dean: West Point, New York, 1996.

[7] J.A. Marin, J.E. Armstrong, and J.L. Kays, "A Framework for an Optimal Experience in Engineering Capstone Design” to be published, Department of Systems Engineering, West Point, New York, 1996.

JOHN A. MARIN is an active duty U.S. Army Lieutenant Colonel. He received his B.S. in Engineering from the United States Military Academy, West Point, in 1979, an M.S. in Operations Research from the Naval Postgraduate School in 1989, and a Ph.D. in Systems Engineering from the University of Virginia in 1995. He is currently an assistant professor in the Department of Systems Engineering at West Point.

JAMES E. ARMSTRONG, JR is an active duty U.S. Army Lieutenant Colonel. He received his B.S. in Engineering from the United States Military Academy, West Point, in 1975, an M.E. in Systems Engineering from the University of Virginia in 1985, and a Ph.D. in Industrial and Systems Engineering from the Georgia Institute of Technology in 1990. He is currently an academy professor in the Department of Systems Engineering at West Point. 